\title{
Factors Affecting Early Marriage in Bangladesh: An Analysis on BDHS, 2014 Data
}

\author{
Shanjida Chowdhury ${ }^{1, *}$, Md. Mahfujur Rahman², Nurul Mohammad Zayed ${ }^{3}$ \\ ${ }^{1}$ Department of General Educational Development, Daffodil International University, Bangladesh. \\ ${ }^{2}$ Comilla University, Kotbari, Cumilla-3506, Bangladesh. \\ ${ }^{3}$ Department of Real Estate, Daffodil International University, Dhaka, Bangladesh.
}

\begin{abstract}
How to cite this paper: Shanjida Chowdhury, Md. Mahfujur Rahman, Nurul Mohammad Zayed. (2020) Factors Affecting Early Marriage in Bangladesh: An Analysis on BDHS, 2014 Data. International Journal of Humanities, Arts and Social Science, 4(1), 40-47.
\end{abstract}

DOI: $10.26855 /$ jhass.2020.01.006

Received: March 28, 2020

Accepted: April 27, 2020

Published: May 14, 2020

*Corresponding author: Shanjida Chowdhury, Department of General Educational Development, Daffodil International University, Bangladesh. Email:

shan_chydiu.ged@daffodilvarsity.edu.b d

\begin{abstract}
Earlier marriage is usual throughout the world and has been enforced as severe and pulverizing outcomes for little kids. Most early marriages in developing countries are occurred with forcing and violating the laws. Early marriage is severely caused by maternal mortality and maternal health. Earlier marriage before the period of 18 years is moreover an impediment to numerous multinational human treaties expresses. Now it is essential to take the necessary steps to overcome this problem, and we should strictly respect the laws of early marriage in Bangladesh. Therefore, the factors affecting the use of early marriage should be clearly understood in Bangladesh. The 2014 Bangladesh Demographic Health Survey data has been operated for this inspection, which is multistage stratified bunched evidence. And here, Logistic Regression has been used to analyze this data. This study applies Binary Logistic Regression to draw an appropriate conclusion about the factors distressing on early marriage.
\end{abstract}

\section{Keywords}

Early marriage, factors, BDHS, Binary Logistic Regression, Bangladesh

\section{Introduction}

Earlier marriage interpreted as a traditional marriage or informal coalition before the period of 18 . Childhood marriage is pervasive and can encourage a lifetime of complications and crises. What is additional, the outcomes of earlier marriage instruct numerous larger sociably consequences of an earlier marriage, including elevated quantities improvement, the progressively sharp expanse of ailment, and a higher rate of wanderers (Jensen and Thornton, 2003). Earlier marriage absolutely destroys the youthful lady's wellbeing and fortune. Marriage is regularly tailed by pregnancy, nonetheless of whether a youthful lady is not yet actually or intellectually capable. According to the June 2019 study by UNICEF, 12 million girls are married before they turn 18 each year, and one in nine girls is married before they turn 15 , especially in the developing world. 650 million girls and women living today around the world were marrying until they turned 18. From a global dataset of UNICEF, 2019, without further acceleration, more than 120 million additional girls will marry before their 18th birthday by 2030 worldwide. Child marriage rates are highest in sub-Saharan Africa, where approximately 4 out of 10 young women were married before age 18, followed by South Asia where 3 out of 10 married before age 18. Bangladesh has some of the highest child marriage rates in the country. Less than half of all girls marry before they hit the minimum age of 18. According to the Child Marriage Restraint Act (1929), the legal marriage age for a girl is 18 
years and for a boy is 21 years in Bangladesh. Despite the law, child marriage is sometimes considered as a social norm in Bangladesh (Islam \& Mhamud, 1996). Many families also claim that marrying girls before they go to puberty will bring blessings to their families (Tristam, 2014). Girls who marry also get under pressure to give birth to a child early in life. Sometimes young women who are tied may furthermore be cited to explicitly transmitted infections, involving HIV. At the level when young ladies wed, they are repeatedly obliged to slip out of school so they can adopt family unit commitments. Earlier marriage likewise confines their opportunities, involving prospective work possibilities, and has lengthy hike influences on their households. This is no acceptance of their entitlement to education (Jensen \& Thornton, 2003; Wodon et al., 2016). Furthermore, the lack of formal schooling has intergenerational consequences too. It makes it harder for girls to get access to and use health information for themselves and their children. Child marriage affects whole populations by leading to a continuing cycle of ill health, violence, and gender inequality. This institutional aspect with concerns to increased rates of earlier marriage illustrates a stitching imperative on an exhibition to earlier marriage openings. Young girls who leave school have more sad wellbeing and monetary outcomes than someone who remains in school, and in the end, their child's admission more awful too. So women who marry younger tend to have less education, have less ability to make decisions in their household, and are more likely to witness domestic violence (Otoo-Oyortey \& Pobi, 2003; Clark, Bruce, \& Annie, 2006; Chatha, Khalil, \& Sajjad, 2014). Considering the context, this research is attempting to examine the related factors that influence early marriage in Bangladesh for establishing and enhancing improved intervention strategies. So primary objective of this study is to explore the factors that are statistically associated with early marriage and also develop an intercept that an early marriage is stunted without adjustment for predictors.

\section{Literature Review}

Early marriage or child marriage is generally described as marriage before the age of 18 and is more common among young girls (NIPORT, 2013). Marriage is an absolutely perceived affair between a man and a female where they are joined explicitly; combine financially, and may have teenagers through birth or allowance (Strong, DeVault, \& Sayad, 1998). There are several factors that are linked to child marriage. The reasons behind early marriage in West and Central Africa are religion, tradition and culture, poverty, and gender inequalities (Johansson, 2015; Wodon et al., 2017). Due to early marriage young girls' physical immaturity results in adverse health effects leading to high maternal and neonatal mortality in sub-Saharan Africa (Larsen, 2009). According to Maheu-Giroux et al. (2016) in their study showed that early childbearing also includes other maternal health issues, including malnutrition, anemia, malaria, sexually transmitted decease, psychiatric disease, and obstetric fistula. The various researcher found that age, education, religion, region, and ethnicity are the most influential factors of child marriage (Kumchulesi et al., 2011). The study of Lowe et al. (2019) cultural background and the fear that girls may engage in premarital sex are two important factors associated with early marriage in the rural Gambia.

In their report, Jain et al. (2011) addressed the incidence of child marriage in India. The causes of child marriage were examined as economic security, the safety of young girls, regulation of female behavior, and socio-cultural and religious values. Based on their outcomes, they also proposed that early marriage can be controlled by making women economically empowered, promoting education, and raising awareness via mass media.

\section{Data and Variables}

\subsection{Data Source}

The data used in this study has been taken from the Bangladesh Demographic and Health Survey (BDHS) conducted in 2014. The 2014 Bangladesh Demographic and Health Survey (2014 BDHS) was implemented under the authority of the National Institute of Population Research and Training (NIPORT), Ministry of Health and Family Welfare. The survey was implemented by Mitra and Associates from June to November 2014. The funding for the 2014 BDHS was provided by the United States Agency for International Development (USAID) of Bangladesh. ICF International provided technical assistance as well as funding through The DHS Program, a USAID funded project. 


\subsection{Dependent Variable}

As the purpose of the study to determine the factors affecting early marriage, the dependent variable is "Age at first marriage" which takes the value "1" for early married and " 0 " for not early married.

\subsection{Explanatory Variables}

Religion, Region, Types of residence, highest education level, Daughter at home, Husband/Partner's occupation, Husband/Partner's Education are the dependent variable.

\section{Methodology}

The present study aims to determine the factors affecting the use of early marriage. As a starting tool for the analysis provides a preliminary idea of how two variables are associated but do not provide an indicator of the causal relationship between them. Therefore, regression analysis is required to explore the form of their relationship. Available regression methods for analyzing binary data are linear probability, logistic regression model, and probit model. Logistic regression, the most popular method of fitting binary data, requires the assumption of independence of the observations. However, data considered in the following study is hierarchical in nature which violates this assumption. To settle down this problem one of the best possible solutions is to use multilevel logistic regression instead of traditional logistic regression. The bivariate analysis allows looking at the associations among two variables. These measures of association relate to how well one variable relates to others and helps to understand this relationship. Contingency tables are used to visually assess whether the variables might be related but it is not sufficient to test a hypothesis about the relationship between two variables. An additional statistic, chi-square, is needed to perform a hypothesis testing about two variables.

\section{Analysis and Result}

\subsection{Introduction}

The exploratory data analysis has been performed to get a visual understanding of the distribution of occurring early marriage across different categories of the explanatory variables. Then a bivariate analysis has been performed to assess percentage distributions of the different variables and association with occurring early marriage. After that to examine the simultaneous effect of all the explanatory variables on the use of early marriage.

\subsection{Univariate Analysis}

Table 1. Frequency Distribution

\begin{tabular}{ccc}
\hline Variables & Categories & Percentage \\
\hline & Sylhet & 16.1 \\
& Barisal & 11.2 \\
Division & Chittagong & 20.0 \\
& Dhaka & 16.5 \\
& Khulna & 11.2 \\
& Rajshahi & 12.4 \\
& Rangpur & 12.6 \\
Type of place of residence & & \\
& Urban & 30.5 \\
& Rural & 69.5 \\
& Islam & 90.3 \\
Religion & Hinduism & 9.3 \\
& Buddhism & 0.2 \\
& Christianity & 0.2 \\
\hline
\end{tabular}




\begin{tabular}{|c|c|c|}
\hline \multirow{4}{*}{ Highest educational level } & No education & 19.3 \\
\hline & Primary & 30.7 \\
\hline & Secondary & 42.2 \\
\hline & Higher & 7.9 \\
\hline \multirow{7}{*}{ Daughters at home } & 0 & 29.7 \\
\hline & 1 & 43.0 \\
\hline & 2 & 18.8 \\
\hline & 3 & 6.0 \\
\hline & 4 & 1.9 \\
\hline & 5 & 0.6 \\
\hline & 6 & 0.1 \\
\hline \multirow{4}{*}{ Husband/partner's occupation } & Agricultural Worker & 69.4 \\
\hline & Non-Agricultural Worker & 18.4 \\
\hline & Good Job & 11.9 \\
\hline & Others & 0.4 \\
\hline \multirow{4}{*}{ Husband/partner's education level } & No education & 28.1 \\
\hline & Primary & 29.2 \\
\hline & Secondary & 29.2 \\
\hline & Higher & 13.5 \\
\hline \multirow{2}{*}{ Age at First Marriage } & not early married & 19.4 \\
\hline & early married & 80.6 \\
\hline
\end{tabular}

Source: Estimated

From Table 1, it can be seen that the highest child marriage occurs in the Chittagong division. In rural area, the incidence of a child, marriage is highest. Out of the total respondents, almost $81 \%$ of respondents married earlier.

\subsection{Bivariate Analysis}

In this section, the bivariate analysis of early marriage is discussed in a table. The result of this analysis and the P-value of the associated $\chi^{2}$ test are shown in the following table.

On bivariate analysis, a cross-tabulation with Chi-square statistics are displayed in Table 2. Divisional variation is obvious and crucial for occurring child or adolescent marriage. Out of 7,046 child marriage, 19.2\% on Chittagong, followed by $16.7 \%$ occurred on Dhaka and $13.9 \%$ on Rangpur. Through residential pattern, $72.1 \%$ nuptial status changes to the rural women before 18 years comes. As a Muslim maximized nation, the occurrence of nuptial engagement significantly occurs at $91.6 \%$ for Muslim adolescents than other religious children. Education is a striking force to root out the havoc of child marriage tradition. At or after the secondary level, the chances of occurring marriage in an immature state is low. This scenario is the same for the husband with same pattern. On the sight of the occupational status of the husband, the possibility of child marriage is larger for agriculture as a profession than other professions. This significant variation occurs due to agricultural-based husbands are not aware of family planning or educational insight. Using the Body mass index, the practice of child marriage is under the thin woman section. Taking the first child at an immature age is risky for both child and woman. This malpractice is still a burning question as it happens on $93.6 \%$ of the mother before 20 years occurred. For a more clear view, we take another variable of the gap between marriage and first child. $78 \%$ of the woman took the first child before 3 years of marriage happen. Some researchers took insight on having a daughter at home is crucial for child marriage. Having one daughter has a $42.1 \%$ chance of being married in the early stage. All of the variables are tabulated with Chi-square statistics under the null hypothesis of no association between early marriage occurrence and control variables. Each variable is rejected at a $1 \%$ level of significance and suggests that there lies a significant association. 
Table 2. Results of Bivariate Analysis

\begin{tabular}{|c|c|c|c|c|c|}
\hline \multirow[b]{2}{*}{ Variables } & \multirow[b]{2}{*}{ Characteristics } & \multicolumn{2}{|c|}{ Age at First Marriage } & \multirow[t]{2}{*}{ Total } & \multirow[b]{2}{*}{ Chi-square } \\
\hline & & not early married & early married & & \\
\hline \multirow{7}{*}{ Division } & Barisal & $146(8.8 \%)$ & $828(11.8 \%)$ & $974(11.2 \%)$ & \multirow{7}{*}{$148.69^{*}$} \\
\hline & Chittagong & $384(23.2 \%)$ & $1,355(19.2 \%)$ & $1,739(20 \%)$ & \\
\hline & Dhaka & $263(15.9 \%)$ & $1,174(16.7 \%)$ & $1,437(16.5 \%)$ & \\
\hline & Khulna & $179(10.8 \%)$ & $800(11.4 \%)$ & $979(11.3 \%)$ & \\
\hline & Rajshahi & $169(10.2 \%)$ & $907(12.9 \%)$ & $1,076(12.4 \%)$ & \\
\hline & Rangpur & $122(7.4 \%)$ & $982(13.9 \%)$ & $1,104(12.7 \%)$ & \\
\hline & Sylhet & $390(23.6 \%)$ & $1,000(14.2 \%)$ & $1,390(16 \%)$ & \\
\hline \multirow{2}{*}{ Residence } & Urban & $693(41.9 \%)$ & $1,965(27.9 \%)$ & $2,658(30.6 \%)$ & \multirow{2}{*}{$124.30^{*}$} \\
\hline & Rural & $960(58.1 \%)$ & $5,081(72.1 \%)$ & $6,041(69.4 \%)$ & \\
\hline \multirow{4}{*}{ Religion } & Islam & $1,399(84.6 \%)$ & $6,455(91.6 \%)$ & $7,854(90.3 \%)$ & \multirow{4}{*}{$81.42^{*}$} \\
\hline & Hinduism & $239(14.5 \%)$ & $575(8.2 \%)$ & $814(9.4 \%)$ & \\
\hline & Buddhism & $8(0.5 \%)$ & $8(0.1 \%)$ & $16(0.2 \%)$ & \\
\hline & Christianity & $7(0.4 \%)$ & $8(0.1 \%)$ & $15(0.2 \%)$ & \\
\hline \multirow{4}{*}{$\begin{array}{l}\text { Woman's } \\
\text { education }\end{array}$} & No education & $161(9.7 \%)$ & $1,512(21.5 \%)$ & $1,673(19.2 \%)$ & \multirow{4}{*}{$1377.48^{*}$} \\
\hline & Primary & $293(17.7 \%)$ & $2,376(33.7 \%)$ & $2,669(30.7 \%)$ & \\
\hline & Secondary & $715(43.3 \%)$ & $2,951(41.9 \%)$ & $3,666(42.1 \%)$ & \\
\hline & Higher & $484(29.3 \%)$ & $207(2.9 \%)$ & $691(7.9 \%)$ & \\
\hline \multirow{4}{*}{$\begin{array}{l}\text { Husband's } \\
\text { occupation }\end{array}$} & Agricultural Worker & $853(51.6 \%)$ & $5,177(73.5 \%)$ & $6,030(69.3 \%)$ & \multirow{4}{*}{$530.44^{*}$} \\
\hline & $\begin{array}{c}\text { Non-Agricultural } \\
\text { Worker }\end{array}$ & $331(20 \%)$ & $1,265(18 \%)$ & $1,596(18.3 \%)$ & \\
\hline & Good Job & $460(27.8 \%)$ & $576(8.2 \%)$ & $1,036(11.9 \%)$ & \\
\hline & Others & $9(0.5 \%)$ & $28(0.4 \%)$ & $37(0.4 \%)$ & \\
\hline \multirow{4}{*}{$\begin{array}{l}\text { Husband's } \\
\text { education }\end{array}$} & No education & $243(14.7 \%)$ & $2,203(31.3 \%)$ & $2,446(28.1 \%)$ & \multirow{4}{*}{$855.48^{*}$} \\
\hline & Primary & $309(18.7 \%)$ & $2,221(31.5 \%)$ & $2,530(29.1 \%)$ & \\
\hline & Secondary & $537(32.5 \%)$ & $2,011(28.5 \%)$ & $2,548(29.3 \%)$ & \\
\hline & Higher & $564(34.1 \%)$ & $611(8.7 \%)$ & $1,175(13.5 \%)$ & \\
\hline \multirow{3}{*}{ BMI of woman } & Thin & $400(24.2 \%)$ & $7,046(100 \%)$ & $7,446(85.6 \%)$ & \multirow{3}{*}{$6239.75^{*}$} \\
\hline & Normal & $1,118(67.6 \%)$ & 0 & $1,118(12.9 \%)$ & \\
\hline & Overweight & $135(8.2 \%)$ & 0 & $135(1.6 \%)$ & \\
\hline \multirow{5}{*}{$\begin{array}{l}\text { Woman's age } \\
\text { at first birth }\end{array}$} & less than 20 & $578(35 \%)$ & $6,597(93.6 \%)$ & $7,175(82.5 \%)$ & \multirow{5}{*}{$3220.52^{*}$} \\
\hline & $21-25$ & $832(50.3 \%)$ & $395(5.6 \%)$ & $1,227(14.1 \%)$ & \\
\hline & $26-30$ & $198(12 \%)$ & $48(0.7 \%)$ & $246(2.8 \%)$ & \\
\hline & $31-35$ & $39(2.4 \%)$ & $5(0.1 \%)$ & $44(0.5 \%)$ & \\
\hline & $36-40$ & $6(0.4 \%)$ & $1(0.0 \%)$ & $7(0.1 \%)$ & \\
\hline \multirow{3}{*}{$\begin{array}{l}\text { Birth space of } \\
\text { first child from } \\
\text { marriage }\end{array}$} & 0-3 years & $1,398(84.6 \%)$ & $5,464(77.5 \%)$ & $6,862(78.9 \%)$ & \multirow{3}{*}{$39.78^{*}$} \\
\hline & 4-6 years & $205(12.4 \%)$ & $1,256(17.8 \%)$ & $1,461(16.8 \%)$ & \\
\hline & more than 6 years & $50(3 \%)$ & $326(4.6 \%)$ & $376(4.3 \%)$ & \\
\hline \multirow{4}{*}{$\begin{array}{c}\text { Daughter at } \\
\text { home }\end{array}$} & No & $559(33.8 \%)$ & $2,037(28.9 \%)$ & $2,596(29.8 \%)$ & \multirow{4}{*}{$60.7^{*}$} \\
\hline & 1 & $770(46.6 \%)$ & $2,968(42.1 \%)$ & $3,738(43 \%)$ & \\
\hline & 2 & $229(13.9 \%)$ & $1,397(19.8 \%)$ & $1,626(18.7 \%)$ & \\
\hline & 3 or more & $95(5.7 \%)$ & $644(9.1 \%)$ & $739(8.5 \%)$ & \\
\hline Total & & 1,653 & 7,046 & 8,699 & \\
\hline
\end{tabular}

Source: Estimated 


\subsection{Multivariate Analysis}

In multivariate context, binary logistic regression is adopted $(0=$ not early married $\& 1=$ early married $)$ in given Table 3. In the case of division, the chance of being early married is 2.825 times significantly more for Rangpur, followed 1.773 times for Khulna, 1.075 times more for Dhaka as compared to the Sylhet division. For residence, the chance of being early married is 0.015 times more for urban adolescents than rural. For the religious aspect, the chance of early married practice is more for Muslim families as compared to Christian, though it is statistically insignificant. Woman's education is crucial for nullifying child marriage. The odds of child marriage are 3.704 times statistically more for illiterate as compared to the higher educated woman. As the educational level increases, the risk of child marriage is statistically decreasing. The education of the husband is also crucial for this regard and 1.61 times more risk for an illiterate husband to be married to the adolescent as compared to a higher educated husband. Birth space of the first child after marriage is significantly associated with marriage in the teenage stage. Other variables like the occupation of husband, BMI of woman, age of the woman at first birth, and daughter at home are insignificant.

Table 3. Results of Multivariate Analysis

\begin{tabular}{|c|c|c|c|c|}
\hline & \multirow{2}{*}{ Coefficient } & \multirow[t]{2}{*}{ Adj. OR } & \multicolumn{2}{|c|}{ 95\% C.I. for Adj. OR } \\
\hline & & & Lower & Upper \\
\hline \multicolumn{5}{|c|}{ Division } \\
\hline Barisal $^{* * *}$ & 0.995 & 2.706 & 1.729 & 4.236 \\
\hline Chittagong & 0.174 & 1.19 & 0.86 & 1.645 \\
\hline Dhaka $a^{* * *}$ & 0.73 & 2.075 & 1.406 & 3.062 \\
\hline Khulna $a^{* * *}$ & 1.02 & 2.773 & 1.762 & 4.366 \\
\hline Rajshahi ${ }^{* * *}$ & 0.896 & 2.449 & 1.564 & 3.836 \\
\hline Rangpur $^{* * *}$ & 1.342 & 3.825 & 2.382 & 6.143 \\
\hline \multicolumn{5}{|l|}{ Sylhet } \\
\hline \multicolumn{5}{|c|}{ Residence } \\
\hline Urban & 0.015 & 1.015 & 0.795 & 1.296 \\
\hline \multicolumn{5}{|l|}{ Rural } \\
\hline \multicolumn{5}{|l|}{ Religion } \\
\hline Islam & 0.859 & 2.36 & 0.274 & 20.315 \\
\hline Hinduism & 0.408 & 1.503 & 0.171 & 13.207 \\
\hline Buddhism & 0.631 & 1.88 & 0.089 & 39.843 \\
\hline \multicolumn{5}{|l|}{ Christianity } \\
\hline \multicolumn{5}{|c|}{ Woman's education } \\
\hline No education ${ }^{* * *}$ & 1.548 & 4.704 & 2.685 & 8.24 \\
\hline Primary $^{* * *}$ & 1.576 & 4.835 & 2.95 & 7.923 \\
\hline Secondary ${ }^{* * *}$ & 1.012 & 2.752 & 1.82 & 4.163 \\
\hline \multicolumn{5}{|l|}{ Higher } \\
\hline \multicolumn{5}{|c|}{ Husband's occupation } \\
\hline Agricultural Worker & -13.587 & 0 & 0 & . \\
\hline Non-Agricultural Worker & -13.626 & 0 & 0 & . \\
\hline Good Job & -13.438 & 0 & 0 & . \\
\hline \multicolumn{5}{|l|}{ Others } \\
\hline \multicolumn{5}{|c|}{ Husband's education } \\
\hline No education ${ }^{* * *}$ & 0.99 & 2.691 & 1.682 & 4.307 \\
\hline Primary $^{* * *}$ & 0.642 & 1.9 & 1.271 & 2.84 \\
\hline
\end{tabular}




\begin{tabular}{|c|c|c|c|c|}
\hline Secondary $^{* *}$ & 0.381 & 1.464 & 1.026 & 2.089 \\
\hline \multicolumn{5}{|l|}{ Higher } \\
\hline \multicolumn{5}{|c|}{ BMI of woman } \\
\hline Thin & 30.762 & $2.29 \mathrm{E}+13$ & 0 & . \\
\hline Normal & -0.51 & 0.6 & 0 & . \\
\hline \multicolumn{5}{|l|}{ Overweight } \\
\hline \multicolumn{5}{|c|}{ Woman's at first birth } \\
\hline less than 20 & 19.096 & $1.97 \mathrm{E}+08$ & 0 & . \\
\hline $21-25$ & -10.689 & 0 & 0 & . \\
\hline $26-30$ & -11.75 & 0 & 0 & . \\
\hline $31-35$ & -12.747 & 0 & 0 & . \\
\hline \multicolumn{5}{|l|}{$36-40$} \\
\hline \multicolumn{5}{|c|}{ Birth space of 1 st child after marriage } \\
\hline $0-3$ years & -29.986 & 0 & 0 & . \\
\hline 4-6 years $^{* *}$ & -1.104 & 0.331 & 0.146 & 0.751 \\
\hline \multicolumn{5}{|c|}{ more than 6 years } \\
\hline \multicolumn{5}{|c|}{ Daughter at home } \\
\hline No & -0.413 & 0.662 & 0.396 & 1.107 \\
\hline 1 & -0.321 & 0.726 & 0.439 & 1.199 \\
\hline 2 & -0.473 & 0.623 & 0.367 & 1.057 \\
\hline \multicolumn{5}{|l|}{3 or more } \\
\hline Constant & -6.192 & 0.002 & & \\
\hline
\end{tabular}

Source: Estimated

\section{Conclusion}

Adolescence or early marriage is a threat to human reproduction. As it lies in south Asian nations as malpractice, woman and children healthy or nutrition issues are still nipped in the bud. To meet the goal of SDG, ensure good woman and children health \& life expectancy is a maiden task. This study adopted the DHS dataset of 2014 for Bangladeshi around 8700 married women. Bivariate and multivariate analysis is carried out to assess the impact of factors affecting child marriage. In bivariate analysis, rural areas have a larger possibility of teenage marriage than urban areas. Chittagong, then Dhaka has comparatively more child marriage traits than others do division. The education of women, as well as husband, has effective power for abolishing child-woman. On multivariate analysis, binary logistic regression, and the impact is clearer of child marriage. The odds of having early-stage nuptial for Rangpur, Khulna, and Rajshahi is high than the Sylhet division. Education of women is more crucial for child marriage practice than a husband's education or any other aspect. Therefore, this study insight on the education of women, husband's education and occupation, birth space, and woman body mass index to improve through using the power of mass media and arranging women's freedom. A woman is still married under the pressure of family and creating dismantle to their family life. Henceforth, family planning issues and child-rearing is crucial for securing both physical and psychological demand. The government needs more alert for stopping child marriage like slow poison in our superstitious society. In addition, we need more consciousness to spread knowledge for ensuring education, opening occupational doors, and building sustainable development.

\section{References}

Bangladesh Demographic and Health Survey (BDHS). (2014). National Institute of Population Research and Training (NIPORT) of the Ministry of Health and Family Welfare. ICF International of Rockville, Maryland, USA and Dhaka, NIPORT, Mitra and Associate

BDHS. (2011). Bangladesh demographic and health survey. National Institute of Population Research and Training (NIPORT). 
Chatha, S. A., Ahmad, K., \& Sheikh, K. S. (2014). Socio-economic Status and Domestic Violence: A Study on Married Women in Urban Lahore, Pakistan. South Asian Studies (1026-678X), 29(1).

Clark, S., Bruce, J., \& Dude, A. (2006). Protecting young women from HIV/AIDS: the case against child and adolescent marriage. International family planning perspectives, 79-88.

Islam, M., \& Mhamud, M. (1996). Marriage pattern and some issues related to adolescent marriage in Bangladesh. Asia-Pacific Population Journal, 11(3), 27-42.

Jain, G., Bisen, V., Singh, S. K., \& Jain, P. (2011). Early marriage of girls as a barrier to their education. International Journal of Advanced Engineering Technology, 2(3), 193-198.

Jensen, R., \& Thornton, R. (2003). Early female marriage in the developing world. Gender \& Development, 11(2), 9-19.

Johansson, N. (2015). Child marriage: the underlying reasons and possible solutions.

Kumchulesi, G., Palamuleni, M., \& Kalule-Sabiti, I. (2011, December). Factors affecting age at first marriage in Malawi'. In InSixth African Population Conference, Ouagadougou-Burkina Faso (pp. 5-9).

Larsen, J. E. (2009). Young people in West and Central Africa: Trends, priorities, investments and partners.

Lowe, M., Joof, M., \& Rojas, B. M. (2019). Social and cultural factors perpetuating early marriage in rural Gambia: an exploratory mixed methods study. F1000Research, 8(1949), 1949.

Maheu-Giroux, M., Filippi, V., Maulet, N., Samadoulougou, S., Castro, M. C., Meda, N., ... \& Kirakoya-Samadoulougou, F. (2016). Risk factors for vaginal fistula symptoms in Sub-Saharan Africa: a pooled analysis of national household survey data. BMC pregnancy and childbirth, 16(1), 82 .

Otoo-Oyortey, N., \& Pobi, S. (2003). Early marriage and poverty: exploring links and key policy issues. Gender \& Development, 11(2), 42-51.

Strong, B., DeVault, C., \& Sayad, B. J. (1996). Core concepts in human sexuality. McGraw-Hill Humanities, Social Sciences \& World Languages.

Tristam, P. (2014). Child marriage: Facts, causes and consequences. World Journal of Social Sciences, 22(1), 35-59.

UNICEF. (2019). For every children. https://data.unicef.org/topic/child-protection/child-marriage/

Whitehead, J. (1995). Modernising the motherhood archetype: Public health models and the Child Marriage Restraint Act of 1929. Contributions to Indian Sociology, 29(1-2), 187-209.

Wodon, Q., M. C. Nguyen, and C. Tsimpo. (2016). Child Marriage, Education, and Agency in Uganda, Feminist Economist, 22(1), 54-79.

Wodon, Q., Male, C., Onagoruwa, A., \& Yedan, A. (2017). Key Findings Ahead of the October 2017 High Level Meeting on Ending Child Marriage in West and Central Africa. Girls' Education and Child Marriage in West and Central Africa. World Bank. 